\title{
PENGARUH DIGITAL CAMPAIGN WEB SERIES SORE TERHADAP KEPUTUSAN PEMBELIAN MELALUI BRAND AWARENESS TROPICANA SLIM STEVIA DI KALANGAN REMAJA-DEWASA MUDA
}

\author{
${ }^{1}$ Rosyifa Ulya Masitha, ${ }^{2}$ Elisabeth Ananda Eka Bonita \\ STIKOM London School of Public Relation Jakarta \\ Email: rosyifaulya@gmail.com
}

\begin{abstract}
Abstrak
Penelitian ini membahas mengenai bagaimana pengaruh digital campaign webseries sore terhadap keputusan pembelian melalui brand awareness produk Tropicana Slim Stevia dikalangan remaja hingga dewasa muda.Hal ini dilandasi oleh ketertarikan peneliti akan webseries SORE yang digunakan oleh Tropicana Slim untuk mengenalkan produk baru mereka yang sasarannya untuk kaum muda.Penelitian ini menggunakan penelitian kuantitatif dengan metode kuesioner sebagai teknik dalam pengumpulan datanya yang disebarkan melalui kuesioner online kepada 100 responden.Hasil akhir dari penelitian ini menunjukan,adanya pengaruh variabel digital campaign terhadap keputusan pembelian,keputusan pembelian terhadap brand awareness dan pengaruh digital campaign serta keputusan pembelian terhadap brand awareness.
\end{abstract}

Kata Kunci: Digital Campaign, Webseries, Keputusan Pembelian,Brand Awareness

\begin{abstract}
This research analyze about how the influence of the digital campaign webseries SORE against purchasing decisions through brand awareness of Tropicana Slim Stevia among teenagers to young adults. It is based by the interest of researchers with webseries SORE used by Tropicana Slim to introduce their new products that are targeted to young people. This research using quantitative research methods questionnaire as a data gathering techniques that distributed through online questionnaires to 100 respondents. The final results for this research are showing that there is influence from digital campaign to purchase decision, purchase decision to brand awareness and also the influence of digital campaign and purchase decision to brand awareness.
\end{abstract}

Keywords: Digital Campaign, Webseries, Purchasing Decisions, Brand Awareness.

\section{PENDAHULUAN}

Perkembangan internet membuat perubahan dalam dunia marketing yang membuat pelaku bisnis lebih mudah untuk memasarkan dan mengkomunikasikan produk atau jasa yang dimiliki ke masyarakat (Khazim, 2016). Dalam penggunaan internet Indonesia masuk dalam urutan ke-empat negara di Asia dengan pengguna terbanyak menurut Internet World Stats. Karena faktor tersebut membuat dunia telah memasuki era digital karena peran penting teknologi dalam membantu kebutuhan manusia membuat setiap individu memilki gaya hidup baru yang ketergantungan akan perangkat elektronik dan jaringan internet (Setiawan, 2017). 
Perkembangan era digital membawa pengaruh bagi pemangku bisnis dalam memasarkan produk atau jasa mereka yang membuat mereka harus memanfaatkan teknologi informasi dan komunikasi digital yang ada untuk lebih dekat dengan target market (brightstar.co.id, 2016). Terbukti melalui survey yang dilakukan oleh APJIII atau Asosiasi Penyelenggara Jasa Internet Indonesia pada tahun 2016 menunjukan jenis konten internet yang diakses oleh pengguna internet di Indonesia dalam kategori komersial sebesar 93,1\%. Maka dapat disimpulkan melakukan kegiatan promosi melalui media internet merupakan salah satu solusi yang baik di era digital.

Dalam melakukan kegiatan pemasaran maupun menyampaikan pesan dan informasi dapat dilakukan dengan berbagai cara salah satunya melalui kampanye. Sebuah kampanye dibuat untuk mengenalkan produk atau jasa, meningkatkan kesadaran merek agar orang lebih mengenal dan tertarik dengan produk ataupun jasa tersebut. Kemajuan teknologi informasi dan komunikasi membuat perancanaan dalam membuat sebuah kampanye pun menjadi lebih beragam. Kampanye dapat dilakukan melalui media digital yang disebut digital campaign, yang penyampaian informasi dan pesannya dilakukan melalui media digital khususnya internet.

Digital campaign adalah salah satu cara yang masih efektif digunakan oleh perusahaan produk maupun jasa dalam membangun brand awareness sekaligus brand enganement terutama untuk beberapa merek Fast Moving Consumer Goods (FMCG) di Indonesia (Wulandari, 2018). Dengan meningkatnya penyebaran akses internet di Indonesia membuat keberhasilan atau keefektifan dari digital campaign meningkat, karena menurut data dari katadata.co.id pada tahun 2015 Indonesia merupakan salah satu negara dengan pengguna internet terbanyak di dunia.

Hal tersebut membuat salah satu merek produsen makanan di Indonesia yaitu Tropicana Slim tertarik untuk menggunakan digital campaign sebagai salah satu cara dalam memperkenalkan produk baru mereka. Melalui teknik digital campaign, Tropicana Slim berkolaborasi dengan Inhype Pictures memilih untuk mempromosikan produk terbaru mereka yaitu Tropicana Slim Stevia melalui webseries yang di unduh ke akun youtube Tropicana Slim. Tropicana Slim pertama kali mengunduh teaser atau cuplikan webseries mereka yang berjudul "SORE" pada awal tahun 2017 tepatnya 15 Januari dan webseries tersebut pertama kali mengunduh episode pertamanya pada 31 Januari 2017.

Tujuan dari penelitian ini adalah untuk mengetahui besarnya pengaruh digital campaign webseries "SORE" terhadap keputusan pembelian melalui brand awareness Tropicana Slim Stevia dikalangan remaja-dewasa muda. Dalam penelitian ini peneliti akan menggunakan teori difusi inovasi sebagai acuan dalam melakukan penelitian.Teori ini meneliti bagaiman ide-ide baru,hal praktis atau objek diadopsi oleh individu-individu dan organisasi.Sejak tahun 1950-an Everette M.Rogers telah mengembangkan model yang sangat komprehensif tentang bagaimana inovasi-inovasi diadopsi (Ardianto, 2011, p. 111).

Tahapan dalam teori ini yang telah direvisi pada tahun 1983 oleh Rogers pada Komunikasa Massa (Romli, 2016) adalah : (1) Tahap Pengetahuan,Tahap ini ketika seseorang belum memiliki pengetahuan mengenai informasi baru sehingga informasi harus disampaikan melalui berbagai saluran komunikasi yang ada seperti media cetak maupun media elektronik. Aplikasinya pada penelitian ini adalah tahapan saat masyarakat belum 
mengetahui adanya produk baru dari Tropicana Slim yaitu Tropicana Slim Stevia. Karena itu pihak Tropicana Slim berusaha untuk menyampaikan adanya produk baru dari Tropicana Slim melalui media sosial melalui bentuk digital campaign webseries SORE. (2) Tahap Persuasi, Tahap ini saat seseorang tertarik pada inovasi dan aktif untuk mencari informasi lebih lanjut mengenai inovasi. Karakteristik dari inovasi adalah kelebihan inovasi, tingkat keserasian, kompleksitas, dapat dicoba dan dapat dilihat. Aplikasinya pada penelitian ini adalah melalui webseries, muncul ketertarikan untuk menyaksikan tayangan tersebut dan menyadari adanya produk baru Tropicana Slim Stevia dan teratik dengan produk tersebut. (3) Tahap Pengambilan Keputusan,Tahap ketika seseorang telah memahami inovasi dan siap untuk mengambil keputusan untuk menerima atau menolak inovasi tersebut setelah sebelumnya menimbang keuntungan/kerugian dari inovasi tersebut. Pada tahapan ini aplikasi untuk penelitian ketika individu telah menyaksikan webseries dan siap untuk mengambil keputusan untuk menggunakan atau tidak menggunakan produk baru Tropicana Slim Stevia. (4)Tahap Implementasi,Tahap ini seseorang akan mencari informasi lebih lanjut dari kegunaan inovasi tersebut.Aplikasinya pada tahapan ini saat individu mencari informasi lebih jelas tentang Tropicana Slim Stevia. (5) Tahap Konfirmasi, Setelah membuat keputusan, seseorang akan tetap mencari informasi mengenai kebenaran dari keputusan mereka dan pada tahap ini seseorang dapat merubah keputusan mereka.

Definisi singkat digital campaign adalah kegiatan terencana yang dilakukan untuk mengkomunikasikan pesan melalui media digital. Perancaan digital campaign yang baik dapat menghasilkan dampak yang positif, keunggulan lainnya perancanaan kampanye melalui digital relative terjangkau. Oleh sebab itu para pelaku digital campaign berusaha untuk memaksimalkan penggunaan media digital dan social media sebaik mungkin (Shaw, 2013).

Untuk mengukur keberhasilan atau keefektifan dari digital campaign dapat dilihat melalui beberapa faktor menurut Brian Solis dalam (Hariyani, 2016) yaitu: (1) Exposure, tahap ini menunjukan usaha dari suatu perusahaan dalam membuat isi dan pesan dari sebuah campaign yang nantinya akan disalurkan melalui media sosial. Dalam tahapan ini dapat diukur melalui banyaknya audience mendapatkan pesan dari konten kampanye yang dilakukan. Contohnya dalam kampanye pada penelitian ini adalah, konten dalam webseries SORE yang memiliki pesan untuk audience dan disampaikan melalui media sosial youtube. (2) Engagement, tahapan ini akan menunjukan pengukuran lebih dalam lagi yaitu berupa kemudahan masyarakat dalam mengakses kampanye tersebut dan seberapa banyak tindakan yang diambil dari pesan kampanye tersebut. Contohnya dalam penelitian ini adalah kemudahan audience dari kampanye yang dilakukan Tropicana Slim dalam mengakses konten kampanyenya dan juga banyaknya viewers yang menonton webseries SORE pada setiap episodenya. (3) Influence,pada tahap ini akan mengukur bagaimana konten maupun pesan yang disampaikan pada kampanye mempengaruhi sikap audience.Contohnya dalam penelitian ini dapat dilihat melalui ketertarikan audience kampanye ini dalam menggali informasi mengenai pesan yang disampaikan dalam kampanye ini. (4) Action, tahap terakhir ini diukur melalui perilaku atau sikap yang diambil oleh audience berkat kampanye yang telah dilakukan.Contohnya dalam penelitian ini dapat diukur saat audience kampanye Tropicana Slim mendapat pesan yang disampaikan oleh Tropicana Slim. 
Brand awareness adalah kemampuan calon pembeli dalam mengenali sebuah merek dan merek tersebut yang pertama kali muncul dibenak mereka saat dihadapkan dengan kategori produk yang sama (Shimp, 2008). Dalam membangun brand awareness terdapat beberapa tahapan yang dilalui menurut David Aaker dalam (Durianto, Sugiarto, \& Sitinjak, 2011) berikut adalah tahapan dalam mencapai brand awareness yaitu ; (1) Unaware Brand,tahap ini berarti masyarakat belum mengetahui atau tidak menyadari akan adanya suatu merek. Dalam penelitian ini tidak lagi menguji tahap ini karena merek yang diuji yaitu Tropicana Slim yang telah didirikan sejak tahun 1979 ada dalam posisi Top Brand pada kategori pemanis rendah/bebas kalori pada tahun 2017 menurut (Top Brand Award, 2017). (2). Brand Recognition, dalam tahap ini masyarakat telah mampu mengenali sebuah merek setelah mendapat bantuan tertentu untuk mengingat merek tersebut. (3) Brand Recall,tahapan ini berarti masyarakat telah mampu mengenali suaru merek tanpa bantuan. (4) Top of Mind,tahap ini merupakan tahap dimana masyarakat mengingat suatu merek secara spontan saat dihadapkan dengan kategori produk yang sama.

Dalam (Kotler \& Keller, 2011) telah mengembangkan lima tahapan saat customer ingin melakukan keputusan pembelian yaitu, (1) Problem recognition, kondisi saat seseorang menyadari bahwa dirinya membutuhkan suatu produk untuk memenuhi kebutuhan hidup mereka. (2) Information search, setelah menyadari adanya kebutuhan dalam memiliki suatu produk,seseorang akan mencari tahu tentang produk yang mereka butuhkan mulai dari mencari tahu tentang kualitas,bahan dan tempat untuk menemukan produk tersebut. (3) Evaluation of Alternatives, saat menemukan produk yang sesuai dengan kebutuhan mereka, seseorang akan membandingkan produk tersebut dengan produk yang sejenis dengan merek yang berbeda.Biasanya mereka akan membandingkan dari segi harga, kualitas, kemudahan mendapatkan produk tersebut. (4) Purchase Decision, langkah selanjutnya adalah saat seseorang telah menentukan akan membeli suatu produk namun muncul lagi keputusan lainnya yang kembali dipertimbangkan contohnya seseorang akan mempertimbangkan untuk membeli brand A di toko A atau membeli brand A di toko B. (5) Postpurchase Behavior, setelah melakukan pembeli akan produk tersebut, customer akan merasakan pengalaman saat menggunakan produk tersebut dan merasakan apa produk tersebut benar mampu untuk memenuhi kebutuhan mereka.

\section{METODOLOGI PENELITIAN}

Metode penelitian ini menggunakan metode kuantitatif dengan pendekatan eksplanasi dan menggunakan paradigma positivism yang artinya penelitian ini berguna untuk menguji hubungan antar variable yang dihipotesiskan untuk diuji kebenarannya dan pengaruhnya terhadap variable yang lain (Ardianto, 2011). Populasi pada penelitian ini adalah subscriber dari akun youtube Tropicana Slim yang pada saat diakses tanggal 27 Oktober 2017 berjumlah 67.400 dan setelah dihitung menggunakan rumus slovin untuk mengetahui jumlah sampelnya mendapatkan hasil sebanyak 100. Teknik pengumpulan data dilakukan dengan cara menyebarkan kuesioner kepada sampel yang diteliti.

Penelitian ini memakai teknik Teknik analisis jalur merupakan alat ukur yang dikembangkan oleh Sewall Wright pada tahun 1934 yang merupakan hasil dari pengembangan korelasi yang diurai menjadi interpretasi. Asumsi dari model analisis jalur 
menunjukan bahwa beberapa variabel sebenarnya mempunyai hubungan yang sangat dekat satu dengan lainnya (Sutopo \& Slamet, 2017).

\section{Hasil Konversi Analisis Jalur}

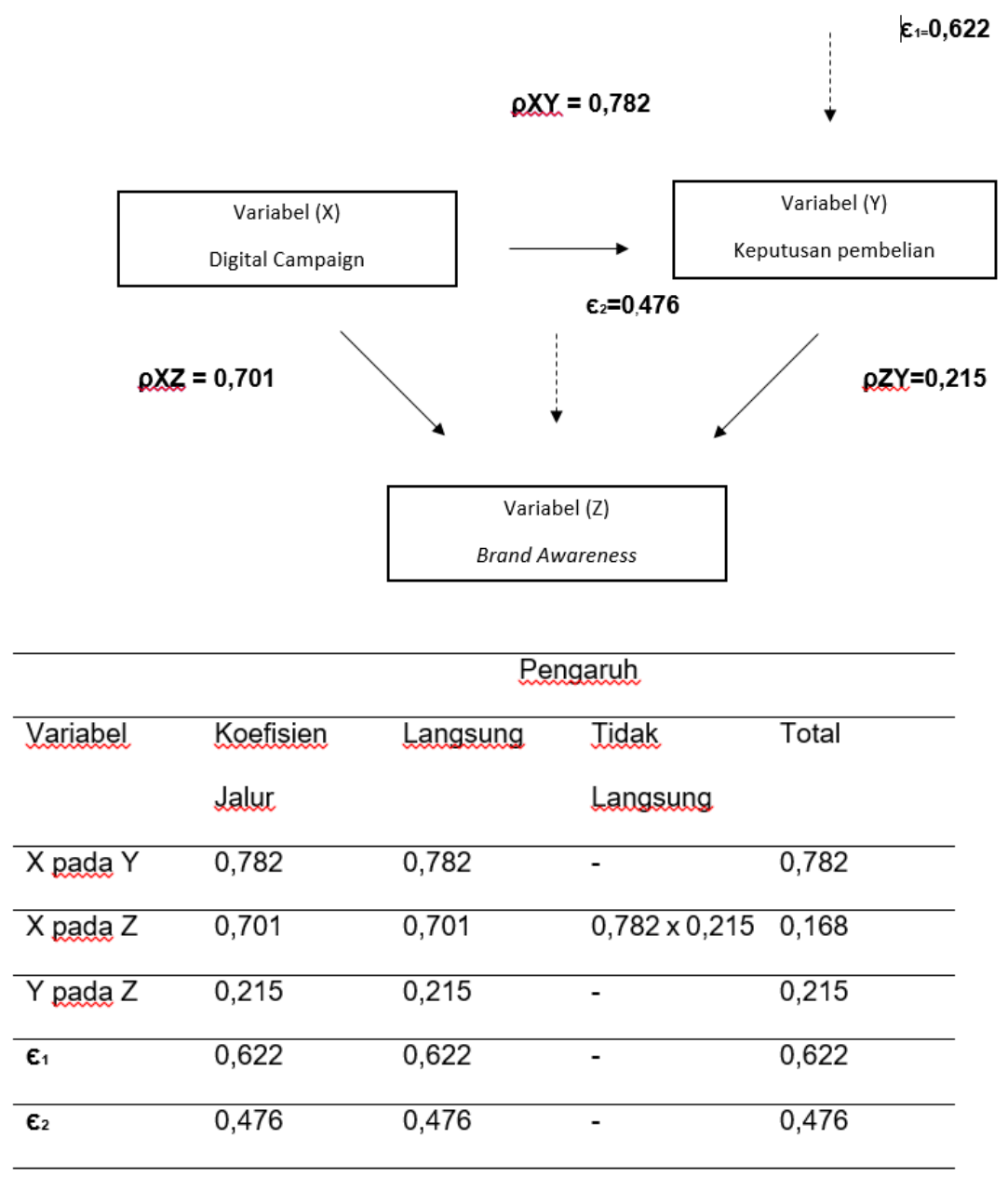

Berdasarkan hasil dari 100 responden dalam penelitian ini dapat dibuktikan bahwa dimensi-dimensi yang digunakan dalam penelitian ini dapat mengukur pengaruh antar variabel adapun dimensi-dimensi yang dimaksud adalah pada variabel $\mathrm{X}$ digital campaign terdapat 4 dimensi,variabel $\mathrm{Y}$ keputusan pembelian terdapat 4 dimensi dan pada variabel $\mathrm{Z}$ digunakan 3 dimensi. Berdasarkan tabel diatas, menunjukan pengaruh langsung variabel $\mathrm{X}$ terhadap variabel $\mathrm{Y}$ sebesar 0,782 , pengaruh langsung variabel $\mathrm{X}$ terhadap variabel $\mathrm{Z}$ sebesar 0,701 dan pengaruh langsung variabel $\mathrm{Y}$ terhadap variabel $\mathrm{Z}$ sebesar 0,215 maka dapat ditarik kesimpulan pengaruh tidak langsung variabel $\mathrm{X}$ dan variabel $\mathrm{Y}$ terhadap variabel $\mathrm{Z}$ sebesar 0,150 .

\section{HASIL DAN PEMBAHASAN}

Dalam penelitian ini, kuesioner online dibagikan kepada 100 responden yang mayoritasnya adalah perempuan sebesar 63\%. Mayoritas didapatkan karena jalan cerita menggambarkan tentang seorang istri yang masa depan yang ingin mnegubah pola hidup 
suaminya. Dalam penelitian yang dilakukan, Tropicana Slim berkolaborasi dengan Inhype Pictures memilih untuk mempromosikan produk terbaru mereka yaitu Tropicana Slim Stevia dengan memakai digital campaign $(\mathrm{X})$ yang memiliki beberapa faktor menurut Brian Solis (Hariyani, 2016), yakni exposure, engangement, influence dan action. Promosi yang dilakukan Tropicana Slim dalam upaya mengambil keputusan pembelian (Y) dari lima tahapan (Kottler \& Keller, 2011), yakni problem recognition, information research, evaluation of alternatives, purchase decision, postpurchase behavir. Tahapan juga dilihat dari bagaimana brand awareness (Z) terbentuk menurut David Aaker (Durianto, Sugiarto, \& Sitinjak, 2011), yaitu unware brand, brand recogition, brand recall, top of mind.

Dari ketiga variabel dalam penelitian ini, dapat disimpulkan bahwa teori yang digunakan oleh penulis terbukti. Teori difusi inovasi meneliti hal praktis yang diadopsi oleh individu dan organisasi (Ardianto, 2011, p.111). Teori terdiri dari beberapa elemen menurut Rogers (Romli, 2016, p.31) yakni inovasi, saluran komunikasi dan jangka waktunya. Elemen inovasi dalam penelitian yaitu digital campaign webseries sebagai media yang akan diteliti sebagai pengaruh dalam membentuk keputusan pembelian melalui brand awareness. Inovasi selanjutnya adalah penggunaan tumbuhan stevia pada gula rendah kalori Tropicana Slim yang kali ini menyasar kaum muda sebagai target market mereka. Dari elemen saluran komunikasi dilihat melalui webseries yang diunggah ke youtube dan digunakan sebagai media untuk memperkenalkan produk baru dari Tropicana Slim. Sedangkan jangka waktu bergantung kedapa proses pengambilan keputusan, inovatifnya seseorang dan kecepatan dalam mengadopsi inovasi dalam sistem sosial.

Uji hipotesis menghasilkan F sebesar 165.247 dan nilai signifikansi sebesar 0.000. Dilihat dari signifikansi pada perhitungan tersebut sebesar 0,000 yang menunjukan angka lebih kecil dari $0,05(0,05>0,000)$. Maka dapat disimpulkan bahwa Ho ditolak dan Ha diterima yang berarti terdapat pengaruh pada variabel (X) Digital Campaign dan variabel (Y) Keputusan Pembelian signifikan terhadap variabel (Z) Brand Awarenes.

Uji determiasi atau r-tabel menunjukkan nilai 0,773 yang berarti Digital Campaign dan Keputusan Pembelian berpengaruh terhadap Brand Awareness sebesar 77,3\%. Sisanya sebesar 22,7\% merupakan faktor lainnya diluar variabel yang tidak diteliti oleh peneliti.

Konversi analisis jalur memberikan hasil akhir yang dapat disimpulkan bahwa penelitian dapat dibuktikan melalui dimenisi-dimensi yang digunakan. Dari hasil yang didapatkan dirangkum supaya menjadi lebih jelas dan didapatkan adanya pengaruh langsung variabel $\mathrm{X}$ terhadap variabel $\mathrm{Y}$ sebesar 0,782 , pengaruh langsung variabel $\mathrm{X}$ terhadap variabel $\mathrm{Z}$ sebesar 0,701 dan pengaruh langsung variabel $\mathrm{Y}$ terhadap variabel $\mathrm{Z}$ sebesar 0,215 maka dapat ditarik kesimpulan pengaruh tidak langsung variabel $\mathrm{X}$ dan variabel $\mathrm{Y}$ terhadap variabel $\mathrm{Z}$ sebesar 0,150 .

Hasil yang diperoleh dari penelitian Digital Campaign dan Keputusan Pembelian terdapat pengaruh sebesar $61,2 \%$ digital campaign webseries sore untuk mendorong atau mempengaruhi keputusan pembelian seseorang untuk membeli produk Tropicana Slim Stevia.

Kesimpulan akhir dalam penelitian membuktikan bahwa variabel $\mathrm{X}$ yaitu digital campaign dan variabel $\mathrm{Y}$ yaitu keputusan pembelian berkontribusi terhadap brand awareness sebagai variabel $\mathrm{Z}$ sebesar $77,3 \%$. Hal tersebut berarti digital campaign yang 
dilakukan oleh Tropicana Slim Stevia melalui webseries SORE dengan tujuan untuk meningkatkan brand awareness produk tersebut mampu berpengaruh terhadap keputusan pembelian dari produk Tropicana Slim Stevia.

\section{PENUTUP}

Dari penelitian yang telah dilakukan, untuk memperdalam hasil penelitian, disarankan untuk penelitian selanjutnya melakukan penelitian kualitatif agar dapat menghasilkan penelitian yang lebih dalam tentang konsep digital campaign yang dapat berpengaruh pada keputusan pembelian dan juga brand awareness. Penelitian dapat pula dilakukan dengan menggunakan populasi yang berbeda agar dapat melihat pengaruh digital campaign pada keputusan pembelian dan brand awareness dengan objek yang berbeda.

Saran kepada Tropicana Slim dan perusahaan lainnya, untuk melakukan kegiatan promosi melalui digital campaign dengan intensitas lebih tinggi serta memperhatikan isi pesan yang akan disampaikan agar dapat menarik faktor keputusan pembelian dan juga brand awareness karena terbukti digital campaign dapat memberi pengaruh positif pada promosi suatu produk dan mempertimbangkan kegiatan promosi melalui internet yang dapat didistribusikan melalui media sosial dan sebagainya.

\section{REFERENSI}

Ardianto, E. (2011). Metodologi Penelitian untuk Public Relations - Kuantitatif dan Kualitatif. In M. Dr. Elvinaro Ardianto, Metodologi Penelitian untuk Public Relations - Kuantitatif dan Kualitatif (p. 111). Bandung: SIMBIOSA REKATAMA MEDIA.

brightstar.co.id. (2016). Bagaimana Efek Digital Marketing di Indonesia Terhadap Pemasaran. Retrieved from brightstar.co.id:

http://www.brightstars.co.id/blog/bagaimana-efek-digital-marketing-di-indonesiaterhadap-pemasaran/

Durianto, D., Sugiarto, \& Sitinjak, T. (2011). Strategi Menaklukan Pasar Menaklukan Pasar Ekuitas Dan Perilaku Merek. Jakarta: PT.Gramedia Pustaka Utama.

Hariyani, I. (2016). Peran Jaringan Sosial Pada Kampanye Lingkungan Di Media . Kajian Ilmu Komunikasi , 90.

Khazim, I. A. (2016). PENGARUH STRATEGI INTERNET MARKETING TERHADAP PERILAKU KONSUMEN LAZADA.CO.ID DALAM BERBELANJA. Jurnal Ekonomi Bisnis , 80.

Kotler, P., \& Keller, K. L. (2011). Marketing Management. New Jersey: Prentice Hall.

Romli, K. (2016). Komunikasi Massa. In K. Romli, Komunikasi Massa (p. 30). Jakarta: Grasindo.

Setiawan, W. (2017). Era Digital dan Tantangannya. Seminar Nasional Pendidikan . 
Shaw, C. (2013). The Campaign Manager :Running and Winning Local Election. New York: Avalon Publishing.

Shimp, T. A. (2008). Advertising Promotion and Other Aspects of Integrated Marketing Communications. Nashville: South-Western College Pub.

Sutopo, E. Y., \& Slamet, A. (2017). Statistika Inferensial. Yogyakarta: Penerbit ANDI.

Top Brand Award. (2017). Top Brand Index 2017. Jakarta: Top Brand Award .

Wulandari, D. (2018, January). Efektivitas Kampanye Digital Le Minerale. Retrieved from mix.co.id: http://mix.co.id/marcomm/brand-communication/digital-brandcommunication/efektivitas-kampanye-digital-le-minerale 